\title{
Selection of the quantity of the allowance at rough treatment of large - size parts from titanium alloy of BT6 (Russian State Standard GOST 19807-91)
}

\author{
T. V. Lomaeva*, S. D. Kugultinov and I. I. Livshits \\ Kalashnikov Izhevsk State Technical University, 7 Studencheskaya street, Izhevsk 426069, Russian \\ Federation
}

\begin{abstract}
The article presents the results of experimental studies of the effect of cutting depth on cutting force and the procedure of assignment of allowance value at rough turning and melting of stamped blanks for largesize parts of rocket equipment from titanium alloy VT6. As a result of the studies carried out, empirical dependence of cutting force on cutting depth was obtained, and method of allocation of allowance value was created, which is very important in processing of large-size stamped blanks.
\end{abstract}

For modern mechanical engineering, a characteristic trend is the use of not only new breakthrough technologies, but also high-quality materials that allow us to produce products with high performance properties. Such materials fully include titanium alloys. The expansion of the scope of their application is due to their physical and mechanical properties. The low-density shape with high mechanical strength results in a high specific strength of titanium alloys. In addition, titanium alloys have corrosion resistance and significant heat resistance up to $500-600^{\circ} \mathrm{C}$. Due to these properties, titanium-based alloys are actively used in the rocket and aerospace industry both in Russia and abroad. However, from the point of view of mechanical processing, titanium alloys have negative properties, such as low thermal conductivity, low elastic modulus, and high chemical activity with respect to oxygen, nitrogen, and other atmospheric gases. An important feature of titanium alloys is that under certain cutting conditions, chip thinning can occur, i.e. the chip shrinkage coefficient, which characterizes the degree of plastic deformation, is obtained less than one, while for most structural materials it is more than 1 [1-3]. Thinning of shavings can lead to the formation of quite thin shavings, which in turn can ignite and burn, which is unacceptable from the point of view of fire safety [4].

Thus, a significant reserve in improving the productivity and ensuring the safety of mechanical processing of titanium alloys is hidden in the rational choice of cutting modes.

Special difficulties arise when cutting large-sized housing parts of rocket technology, which are associated with the duration of processing. In this case, to reduce the labor intensity and cost of processing, the rough allowance should be removed in one pass. At the same time, the allowance value can reach $30 \mathrm{~mm}$ or more for stamped work pieces. In the

* Corresponding author: lomaeva@yandex.ru 
appointment of modes of cutting with the aim of reducing the complexity of processing should be set to the maximum value of depth of cut for the roughing passes.

Cutting of large-sized body parts is performed on universal equipment that has a certain power of main-motion drives. The dimensionality of the main drive can be determined by the formula (1) $[5,6]$ :

$$
N_{\text {motion drive }}=\frac{60 \cdot P_{z} \cdot v}{\eta}
$$

where $P_{z}$ is the tangential component of the cutting force, $\mathrm{kN}$;

$v$ - cutting speed, $\mathrm{m} / \mathrm{min}$;

$\eta$ - coefficient of performance.

The amount of cutting force is influenced by both the physical and mechanical properties of the material being processed, the geometry of the cutting tool, the tool material, and the cutting modes. It is obvious, that the greater the cutting depth, the wider the cut layer is and the greater the forces needed to cut it off.

Thus, it is important to know how the cutting depth affects the cutting force $P_{z}$ when processing titanium alloy VT6 in order, that depending on the power and drive of the main movement, it would be possible to assign the maximum allowable allowance to be removed.

The dependence of the cutting force $P_{z}$ on various machining factors can be determined using the empirical formula (2) [5]:

$$
P=C_{P} \cdot t^{x} P \cdot S_{o}^{y} P \cdot v^{z} P \cdot K_{1} \cdot K_{2} \cdots K_{i}
$$

where $t$ - depth of cut, $\mathrm{mm} ; S_{o}$, - feed, $\mathrm{mm} / \mathrm{Rev} ; v$ - speed of cutting, $\mathrm{m} / \mathrm{min} ; x_{p}, y_{p}, z_{p}-$ exponents; With $_{R}-$ matching coefficient; $K_{l}, K_{2}, \ldots K_{i}$ - coefficients taking into account processing conditions.

Despite the fact that currently there is a large reference material for calculating the cutting force value when processing various materials, there are no data on the values of the degree indicators for the titanium alloy VT6.

Therefore, experimental studies were conducted to determine the effect of cutting depth on cutting force, chip shrinkage during machining and to determine the degree of $x_{p}$ index for titanium alloy VT6.

A hot-rolled rod made of VT6 titanium alloy with a diameter of $60 \mathrm{~mm}$ was used as a sample for experimental studies of the effect of the cutting depth on the cutting force and chip shrinkage. The research was carried out using a special complex including: a 1I611 lathe, a cutter with Sandvik Coromant load cells pasted on it PSSNP 202OK12, equipped with SNMM $120408 \mathrm{E}$ - NR2HF 10 carbide plates (rear angle $\alpha=7^{\circ}$, angle of inclination of the main cutting edge $\lambda=0^{\circ}$, front angle $\gamma=8^{\circ}$ ), a laptop. The experiment was performed at constant feed and cutting speed ( $\mathrm{So}=0.15 \mathrm{~mm} / \mathrm{Rev}, \mathrm{v}=18.86 \mathrm{~m} / \mathrm{min}$ ).

In the course of research, the transverse shrinkage coefficient of chips was used to assess the degree of plastic deformation (3):

$$
\xi_{a}=\frac{a_{c m p}}{a_{c p . c л .}}
$$

where $a_{s t r}-$ chip thickness, mm;

$a_{c f . S L}-$ the thickness of the cut layer, $\mathrm{mm}$.

The results of experimental studies were summarized in table 1 , and according to the obtained data, the graphs presented in figures 1 and 2 were constructed 2. 
Table 1. The effect of cutting depth on the amount of cutting force and on the amount of chip shrinkage.

\begin{tabular}{|c|c|c|c|c|c|c|c|c|c|c|}
\hline \multirow[t]{2}{*}{$\mathrm{t}, \mathrm{mm}$} & \multicolumn{4}{|c|}{$\begin{array}{l}\text { Value of the cutting force } \\
\mathrm{P}_{\mathrm{z}}(\mathrm{N}) \text {, with the cutting } \\
\text { depth value } \mathrm{t}(\mathrm{mm})\end{array}$} & \multicolumn{4}{|c|}{ and $_{\text {page }}$} & \multirow[t]{2}{*}{ and ${ }_{\text {Ms. CL. }}$} & \multirow[t]{2}{*}{$\xi$} \\
\hline & 1 & 2 & 3 & average & 1 & 2 & 3 & average & & \\
\hline of 0.4 & \multicolumn{4}{|c|}{ was not measured } & 0,17 & 0,18 & 0,17 & 0,173 & 0,106066 & 1,63106 \\
\hline of 0.7 & \multicolumn{4}{|c|}{ was not measured } & 0,15 & 0,14 & 0,145 & 0,145 & 0,106066 & 1,367073 \\
\hline 1 & 552 & 564 & 558 & 558 & 0,105 & 0,1 & 0,11 & 0,105 & 0,106066 & 0,98995 \\
\hline 1,3 & 665 & 671 & 672 & 669 & 0,115 & 0,105 & 0,11 & 0,11 & 0,106066 & 1,03709 \\
\hline 1,5 & 757 & 748 & 748 & 749 & 0,105 & 0,11 & 0,1 & 0,105 & 0,106066 & 0,98995 \\
\hline 1,7 & 790 & 795 & 788 & 791 & 0,105 & 0,1 & 0,1 & 0,101 & 0,106066 & 0,952237 \\
\hline 2 & 871 & 868 & 886 & 875 & 0,1 & 0,08 & 0,08 & 0,086667 & 0,106066 & 0,817104 \\
\hline
\end{tabular}

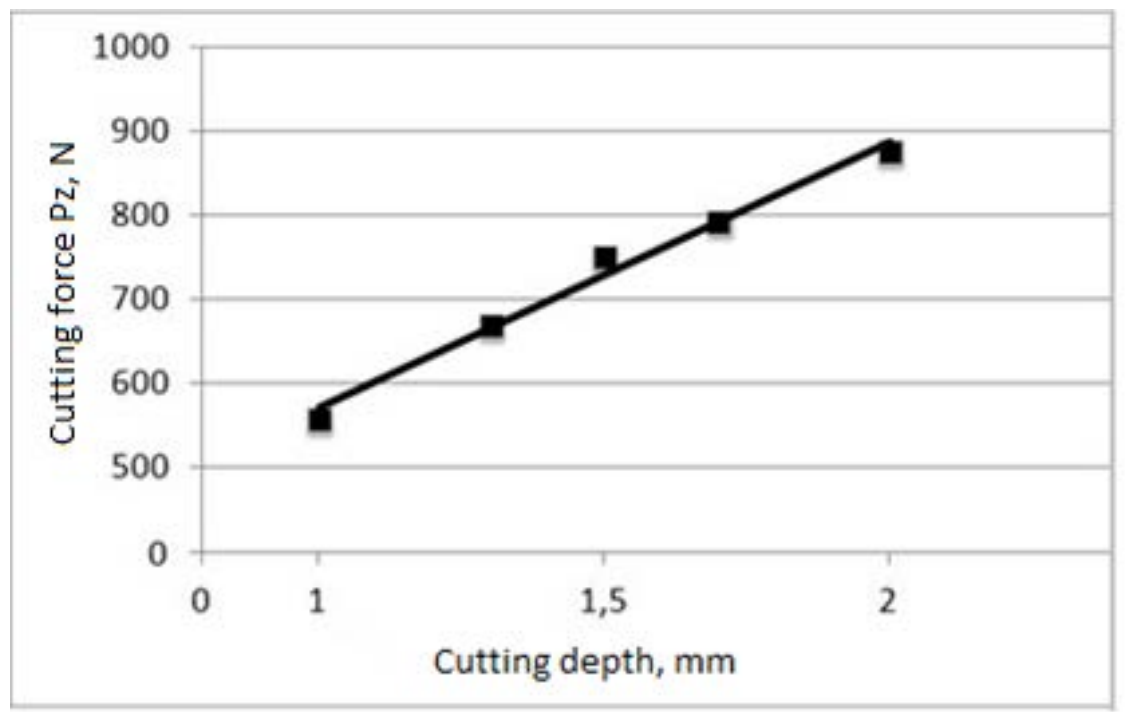

Fig. 1. Dependence of cutting force on cutting depth $\left(S_{o}=0.15 \mathrm{~mm} / \mathrm{Rev} ; v=18.86 \mathrm{~m} / \mathrm{min}\right)$

After processing the data presented in figure 2, an expression describing the dependence of cutting force on cutting depth was obtained:

$$
P_{z}=558 \cdot t^{0,649}
$$

Thus, knowing the power of the drive of the main movement of a particular machine and using the obtained dependence (4) of the cutting force on the cutting depth, we can 
assign the maximum possible cutting depth for 1 pass when processing shell parts of rocket technology made of titanium alloy, and thereby reduce the complexity of manufacturing these products.

The method of assigning the maximum possible cutting depth for roughing large parts of rocket technology can be represented in the form of a diagram shown in figure 2 .

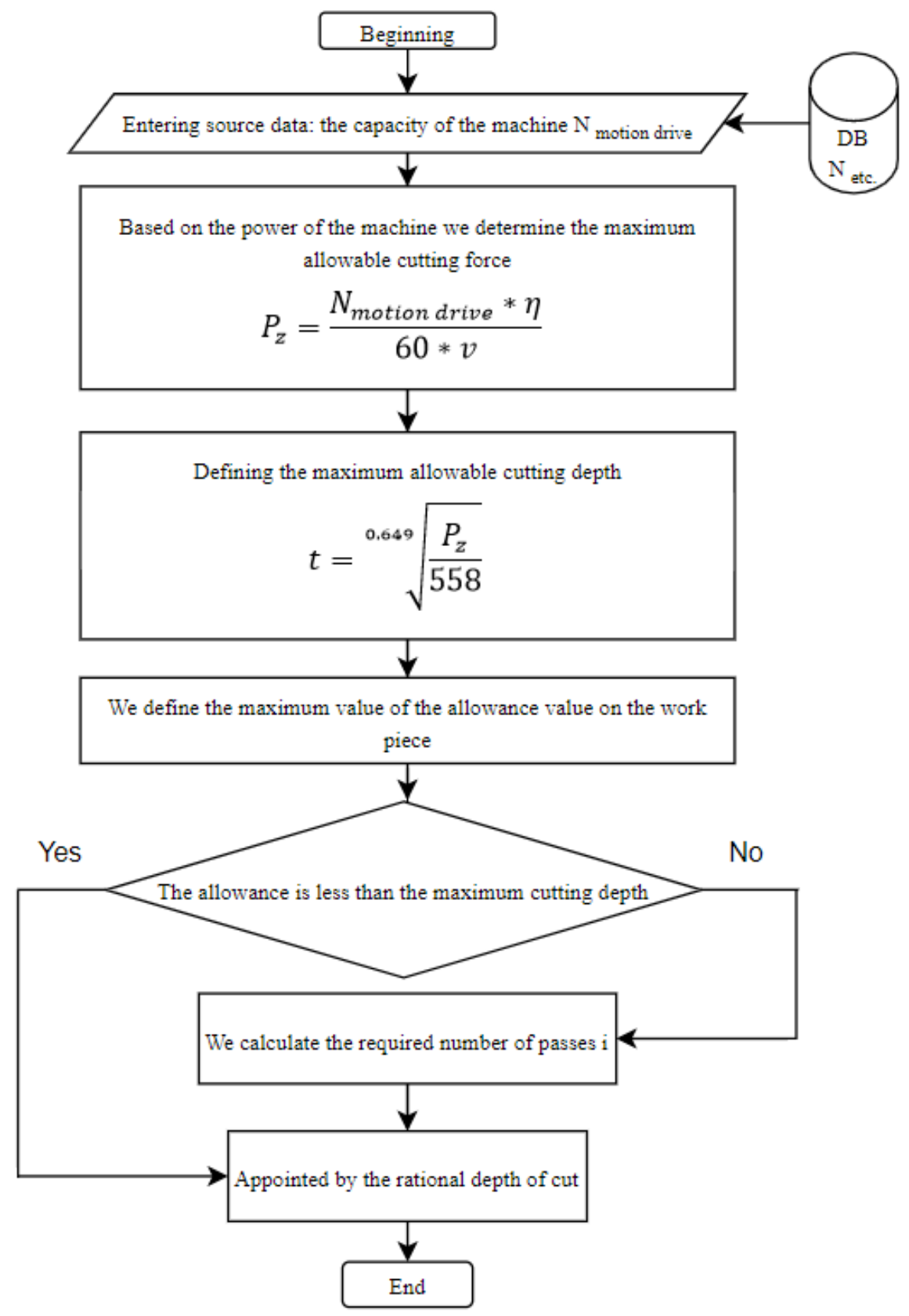

Fig. 2. Block diagram of determining the maximum cutting depth when roughing large-sized parts made of titanium alloy VT6 
After analyzing the resulting expressions (4) it can be concluded that the depth of cutting when machining titanium alloy VT-6 in a sufficiently strong degree affects the cutting force, but its effect is significantly weaker than when processing structural steels, such as steel 4, for which the degree index $x_{p}=1$.

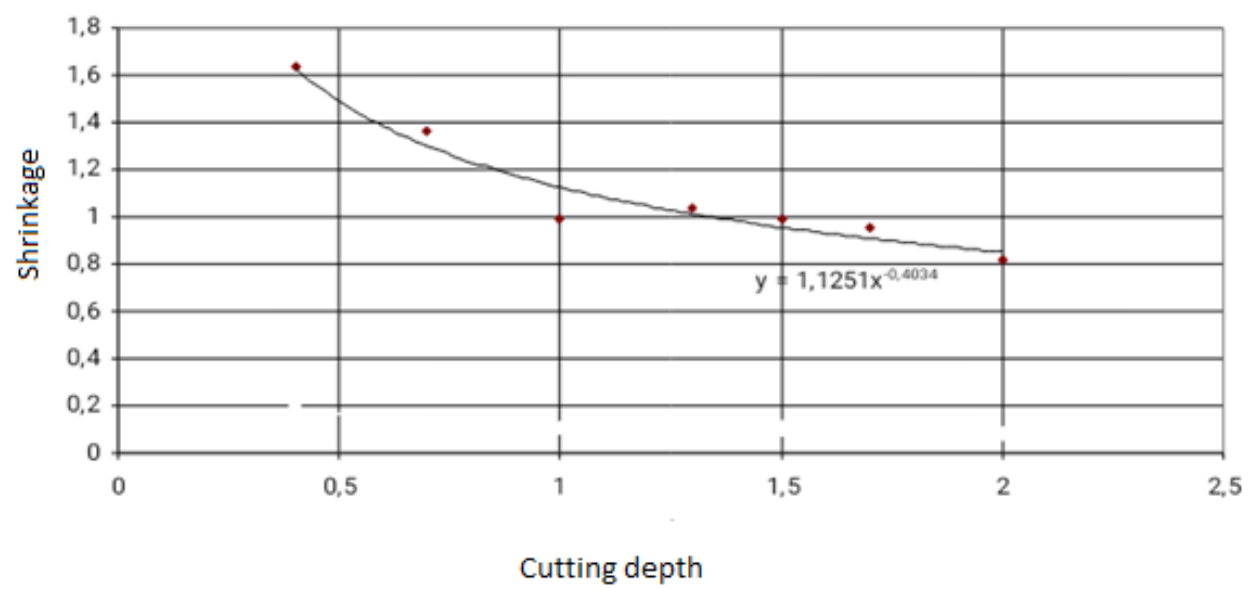

Fig. 3. Dependence of the chip transverse shrinkage coefficient on the cutting depth $\left(S_{o}=0.15\right.$ $\mathrm{mm} / \mathrm{Rev} ; v=18.86 \mathrm{~m} / \mathrm{min}$ )

From the graph, shown in Fig. 3 it can be seen that the chip shrinkage coefficient decreases with increasing cutting depth, and at $t>1.3 \mathrm{~mm}$ the chip shrinkage becomes negative (i.e. less than 1). From here, we can draw the following conclusion: when increasing the cutting depth in order to increase the cross-section area of the cut layer to avoid ignition and chip burning, it is necessary to increase the thickness of the cut layer, which depends on the feed and the main angle in the plan $\phi$. In roughing conditions, the feed values are, usually, set to be sufficiently large, so the conditions necessary for chip ignition are not created.

\section{References}

1. Koryagin S I, Pimenov I V, Khudyakov V K 2000 Methods of Material Processing. Educational book. (Kaliningrad: Kaliningrad State University) 448 p.

2. Zhuchkov N S, Bespakhotny P D, Chubarov A D et.al. 1989 Machining efficiency improvement of titanium alloy workpieces (Moscow: "Mashinostroenie") 152 p.

3. 018 Machining of steels, heat-resisting and titanium alloys considering their physical and mechanical properties. (Moscow: TECHNOSPHERA) $508 \mathrm{p}$.

4. SIOWSH 27.4-1.42-62 Safety regulations for smelting and machining of titanium and its alloys (ratified by the Presidium of the Central Committee, airplane and defense industry on July 30, 1962)

5. Kuguldinov S D, Kovalchuk A K, Portnov I I 2006 Processing technology of structural materials (Moscow: Bauman Moscow State University Publishing House) 671 p.

6. Kuguldinov S D, Kovalchuk A K, Portnov I I. 2008 Processing of materials applied in rocketry (Moscow: Bauman Moscow State University Publishing House) 194 p. 